\title{
Blocos Lógicos e Games: Utilizando Interfaces Tangíveis para a Aprendizagem da Lógica Matemática
}

\author{
Mateus Belli \\ Universidade do Vale do Itajaí \\ Itajaí, SC, Brasil \\ mateusbelli@edu.univali.br
}

\author{
Adriana Gomes Alves \\ Universidade do Vale do Itajaí \\ Itajaí, SC, Brasil \\ adriana.alves@univali.br
}

\begin{abstract}
This article approaches the research in the area of tangible interfaces applied to technology-mediated educational processes, in a perspective of accessibility in digital games. The general objective of the study is to evaluate the use of logic blocks as a tangible interface in a digital game for learning mathematical concepts. The methodology is based on an exploratory research that includes the bibliographic survey and the development of elicitation activities and requirements analysis, design and software development. Logic blocks are used, material recognized for learning mathematical concepts, as control interface of the developed digital game. A digital game was produced, as well as the expansion of research on accessible interfaces and the evaluation of the solution proposed by teachers and students with and without disabilities.
\end{abstract}

\section{KEYWORDS}

Digital Games, Accessibility, Universal Design

\section{INTRODUÇÃO}

A política de inclusão educacional para as pessoas com deficiência exige uma série de mudanças nos processos pedagógicos em virtude das especificidades dos sujeitos atendidos. Essas mudanças requerem a adaptação metodológica e de instrumentos pedagógicos que viabilizem o acesso da pessoa com deficiência ao conhecimento, com vistas a melhoria da qualidade de vida, independência intelectiva e desenvolvimento integral.

Na perspectiva de adaptação de instrumentos pedagógicos, as TICs - Tecnologias da Informação e Comunicação - geram novos valores e pautas de interação e comportamento social [7]. Nessa linha, destacam-se os jogos digitais acessíveis que possibilitam a interação entre o usuário e o jogo e são utilizados tanto para o lazer e entretenimento, como para a educação, reabilitação e participação de todos.

Uma efetiva inclusão requer que todos possam usufruir das mesmas oportunidades existentes, nas condições exigidas. Neste sentido a abordagem que se mostra adequada é o design universal, o qual refere-se ao conceito de projetar todos os produtos e construções de forma a serem utilizados pelo maior número de pessoas possível, independentemente de suas características físicas, idade, e condições sociais. Segundo [7], o design universal designa um método que provê ao usuário um ambiente ou um produto que ele consiga usar, não importando a sua idade, capacidade física ou condição social. Ainda, Design Universal caracteriza-se por não necessitar de adaptações ou design especializado, ou seja, as pessoas utilizam o mesmo produto ou construção [2].
O design universal pode ser facilitado pela adoção de recursos de interação natural, por meio da utilização de dispositivos não convencionais de interação, dentre os quais se destacam as interfaces tangíveis. As interfaces tangíveis são uma abordagem que visam embutir elementos computacionais em materiais concretos, possibilitando novas interações com os computadores que vão além dos tradicionais periféricos teclado e mouse. Essas interações permitem ampliar as experiências dos usuários por meio de elementos mais próximos ao contato natural com objetos.

Considerando o ensino e a aprendizagem da matemática e seus conceitos, o uso de objetos concretos para compreensão e abstração dos conceitos é um recurso didático amplamente utilizado pelos professores. Por tratar-se de um material aberto, o uso do instrumento requer dos professores conhecimentos de atividades instigantes para promover a aprendizagem por meio desses objetos. Aliar os conceitos de jogos digitais e interfaces tangíveis aos já consolidados blocos lógicos utilizados na escola, apresenta-se como uma abordagem promissora de investigação. Nessa perspectiva é que se apresenta este artigo, no sentido de investigar a aplicação dos blocos lógicos como materiais concretos para interface de um jogo digital para aprendizagem de conceitos matemáticos, visando a acessibilidade de crianças com deficiência.

Os blocos lógicos são uma ferramenta poderosa para a aprendizagem de conceitos matemáticos, devido aos diversos usos que dela se pode fazer [8]. Por ser um material aberto à diferenciadas atividades, exige do professor conhecimento ou criação de atividades didáticas utilizando o recurso. Muitos professores usam a ferramenta de maneira limitada, repetindo exercícios simples ou utilizando os blocos como um brinquedo de "montar". O desenvolvimento de um jogo digital utilizando os blocos lógicos como interface visa auxiliar educadores e alunos no ensino e aprendizagem de matemática, ampliando a criatividade e as bases lógicas da criança e do adolescente por meio de interações divertidas e criativas. Desta forma, neste artigo apresentam-se os resultados desta pesquisa, discutindo-se o uso desse material como interface e o jogo digital elaborado para seu uso. Assim, na seção 2 apresentamos os blocos lógicos e as interfaces tangíveis, conceitos fundamentais desta pesquisa; a seção 3 apresenta os trabalhos relacionados; a seção 4 discutimos a metodologia adotada no desenvolvido do trabalho; a seção 5 apresenta os resultados e discussões, incluindo o jogo digital construído e; por fim, a seção 6 apresenta as considerações finais desta pesquisa.

\section{CONCEITOS}

A base da matemática nas escolas é dedicada aos números e seu estudo. Devlin [1] discute que esse fato faz com que a maior parte das pessoas compreenda a matemática como sendo única e exclusivamente números e aritmética. Entretanto é importante evidenciar 
que "os números não têm existência concreta como os objetos que vemos ao nosso redor" [1]. As dimensões, as cores, as formas são conceitos abstratos que representam propriedades dos objetos, assim como um número representa uma propriedade dos conjuntos de objetos. Um objeto, dois objetos. Mas o objeto não tem a propriedade "dois".

A aprendizagem de matemática é favorecida quando utilizados objetos (concretos) que apoiem a construção do pensamento abstrato. Assim, o uso de tecnologia que permita a interação natural do estudante com objetos concretos é uma alternativa para atender a esta necessidade de aprendizagem. Desta forma, foram utilizados os blocos lógicos juntamente com os conceitos de interfaces tangíveis.

\subsection{Os Blocos Lógicos}

Os blocos lógicos são um conjunto de 48 peças de plástico ou madeira criados pelo matemático russo Zoltan Paul Dienes. Este recurso é fundamental na construção das primeiras estruturas lógico matemáticas, permitindo exercícios de lógica que evoluem o raciocínio abstrato. Os blocos utilizam noções de graduação, proporção, comparação, classificação, entre outros, para a aprendizagem. Este tipo de recurso educativo estimula a criança para que aprenda e desenvolva diversos conceitos matemáticos, por exemplo, forma, espessura, tamanho, noção de conjuntos, cor, dentre outros [7].

Os blocos lógicos são dotados de diversas propriedades para estimular e desenvolver o raciocínio da criança. Quanto à cor utilizam o amarelo, o azul e o vermelho. Em termos de forma apresenta o círculo, o quadrado, o triângulo e o retângulo. No que diz respeito ao tamanho, apresentam o grande e o pequeno e à espessura, o grosso e o fino. A figura 1 apresenta um conjunto de blocos lógicos de madeira.

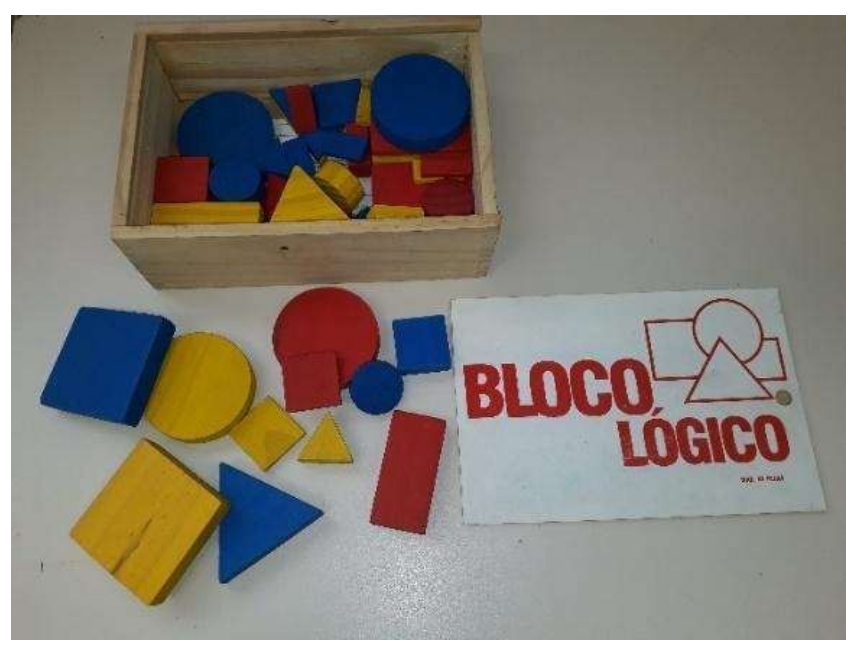

Figura 1: Blocos lógicos de madeira

Os blocos lógicos são uma ferramenta amplamente usada na matemática e têm uma grande amplitude de usos, instigando a criatividade e o raciocínio lógico, podendo, também, ser integrados no aprendizado de outras áreas de conhecimentos, como artes e lógica de programação, por exemplo. Existem diferentes maneiras de introduzir os blocos às crianças. Por exemplo, o professor pode propor a atividade para as crianças escolherem apenas blocos lógicos da cor azul ou blocos de tamanho pequeno. Entretanto, de acordo com [8], os docentes utilizam os blocos lógicos de forma incipiente e pouco sabem a respeito das ricas possibilidades de exploração inerentes ao material.

Aliar o uso dos blocos lógicos com recursos tecnológicos por meio de um jogo digital pode proporcionar a aprendizagem dos conceitos de forma ampliada. Os blocos, objetos concretos, adquirem novos significados quando transpostos para o meio digital. Este recurso pode auxiliar a compreensão dos conceitos matemáticos abstratos. A abordagem para tal intento encontra-se nos conceitos de interfaces tangíveis.

\subsection{Interfaces Tangíveis}

As interfaces tangíveis segundo [5] "podem ser definidas como aquelas que compreendem interações realizadas em artefatos físicos, como estímulos para interferir no contexto e representações de informação digital”. A interface tangível tem esse nome para se contrastar com as interfaces intangíveis que os computadores apresentam normalmente. Enquanto as intangíveis são apenas controladas por meio de interfaces gráficas, as interfaces tangíveis tentam trazer o controle para algo mais próximo da realidade, com objetos físicos que o usuário pode manipular juntamente com estímulos audiovisuais provenientes do computador. Ou seja, a motricidade do usuário ganha importância, uma vez que sua cinestesia se torna a forma como ele interage com a interface. Isto propicia uma maneira mais ampla de interação ao compararmos com os movimentos dos olhos e dos dedos com as interfaces gráficas. As interfaces tangíveis podem proporcionar novas experiências do usuário e favorecerem a aprendizagem de alunos. Para [12] aprender conceitos abstratos é muito difícil, por isso as vantagens das interfaces tangíveis como ferramenta de ensino para problemas de domínio abstrato são:

- Engajamento sensorial: a maneira natural como a criança aprende, envolvendo múltiplos sentidos (no caso tato, visão, audição) em um processo construtivo;

- Acessibilidade: incrementa dramaticamente a acessibilidade para crianças pequenas, para pessoas com deficiências de aprendizagem, e para novatos;

- Aprendizagem colaborativa: provê uma interface colaborativa, não dando o controle para apenas uma pessoa, facilita a interação natural de grupos, e promove a discussão em grupo. [12]

De acordo com [10], vários dispositivos têm agregado conceitos de interfaces tangíveis para interface com os usuários. A lista é extensa e vai de carros e celulares à notebooks, pois os dispositivos multitoque se tornaram comuns nos nossos dias.

As lousas inteligentes, por exemplo, representam outra classe de dispositivos tangíveis. Em geral suportam atividades colaborativas em ambientes compartilhados remotamente, o acesso pode ser distribuído.

O trabalho de [4] cria um ambiente com realidade aumentada baseado em RFID/NFC. O RFID consiste em uma antena e um transceptor que lê frequências de rádio e passa os dados para um dispositivo. 


\section{TRABALHOS RELACIONADOS}

O trabalho de [9] cria um jogo educativo utilizando como controle do jogo interfaces tangíveis. O jogo tem como o objetivo ensinar conceitos básicos de algoritmos. No jogo, são utilizados blocos com marcadores e o celular para interagir com o jogo e responder de maneira sonora para o jogador.

O trabalho de [6] cria um ambiente em que os usuários podem interagir figuras objetos e seres marinhos, como foco para as tartarugas marinhas. O sistema apresenta uma câmera que capta as informações das figuras e apresenta na tela. Os objetos realizam interações entre si com o intuito de ensinar o usuário, de maneira simples e divertida, sobre o mundo marinho. O trabalho dos autores utilizou o conceito de interfaces tangíveis para o seu desenvolvimento.

O trabalho de [3] desenvolve uma solução com o uso da interface tangível para ensinar percepção de objetos pelo toque e conceitos de ambiente espacial em pequena escala para crianças com deficiência visual. O objetivo do sistema é permitir que as crianças possam sentir objetos e depois colocar eles em cima de uma mesa transparente para que o software desenvolvido reconheça os objetos.

\section{METODOLOGIA}

O desenvolvimento da pesquisa pautou-se nos estudos dos referenciais teóricos e trabalhos correlatos na área da educação por meio de blocos lógicos e extensão da sala de aula por meio de tecnologias educacionais utilizando interfaces tangíveis.

Para o desenvolvimento do jogo foram identificadas na literatura atividades que ajudem a criança no desenvolvimento da lógica e da matemática, implementando-os em software, e permitindo a interação com os blocos lógicos físicos. Esta pesquisa também incluiu a entrevista com pedagoga para elicitação dos requisitos do software desenvolvido.

A metodologia da pesquisa consistiu em três etapas: A primeira etapa refere-se a pesquisa bibliográfica e o levantamento das recomendações na bibliografia, com foco no ensino da matemática e da lógica, especialmente para computadores pessoais. Nesta etapa foram consultados artigos, livros, teses e dissertações na área. $\mathrm{O}$ resultado foi a compilação das informações e o material teórico necessário para a segunda etapa do projeto.

A segunda etapa está pautada na especificação do software e seu desenvolvimento. Para tanto foi adotada uma metodologia de prototipação para elencar os requisitos do produto. Esta etapa incluiu o estudo da abordagem tecnológica (linguagem de programação, estratégias de reconhecimento dos objetos e equipamentos) necessários a implementação do produto projetado. Incluiu também as atividades de programação.

A terceira etapa foi a avaliação do jogo desenvolvido, visando verificar caso os objetivos definidos na sua especificação foram atendidos. A avaliação foi feita somente em laboratório, até o momento da escrita deste artigo.

\section{RESULTADOS E DISCUSSÕES}

O desenvolvimento do jogo digital procurou alinhar a utilização dos blocos lógicos com a acessibilidade, aplicando os conceitos de design universal. Para isso, foi utilizado o motor gráfico Unity juntamente com a biblioteca Vuforia. A biblioteca é utilizada para a criação de ambientes de realidade aumentada [11]. No caso do jogo, a utilização da biblioteca se encontra na etapa de passagem dos blocos lógicos para o computador.

\subsection{Reconhecimento de Blocos Lógicos}

A base do desenvolvimento está na relação interação entre o jogador, o bloco lógico e o jogo. Os blocos precisam ser reconhecidos pelo software para que a interação aconteça. Encontramos no trabalho de [10] o uso de interfaces tangíveis, utilizando da visão computacional, para o ensino de lógica de programação com retornos sonoros. Nesse trabalho, são identificados a posição e o ângulo dos blocos para compilar o pseudocódigo e executar o desejado. A identificação dos blocos foi feita com base em linhas feitas no tabuleiro assim como nas formas e desenhos feitos em cada um dos blocos. Este mesmo recurso foi adotado na nossa pesquisa, pois o reconhecimento dos blocos lógicos não é possível com a biblioteca Vuforia. Esta, de acordo com seus criadores, requer que o objeto a ser reconhecido seja rico em detalhes, apresente bom contraste, não possua padrões e formato repetitivos [11]. Os blocos lógicos não se encaixam em nenhum dos atributos desejados, já que todos são monocromáticos e de forma única. Assim, para que a biblioteca conseguisse identificar os objetos, foram adicionados, em cada peça, um adesivo diferente. Desta forma a biblioteca não irá identificar o objeto em si, mas a imagem associada a ele.

Uma vez que as imagens nos blocos trarão mais uma informação ao jogador, optou-se por utilizá-las também no jogo, de forma a se tornar parte integrante do mesmo. Então, além de interações com a forma, o tamanho e a cor de cada um dos blocos, foi criada a interação com a imagem associada. Essas imagens são simples, mostrando objetos do universo infantil, como carrinhos, ursinhos de pelúcia e bonecas, coloridos de maneiras diferentes cada um, associados a blocos aleatórios, para o jogador não fazer associação entre a imagem e o bloco. A Figura 2 apresenta exemplos de imagens que foram adesivadas aos blocos lógicos.

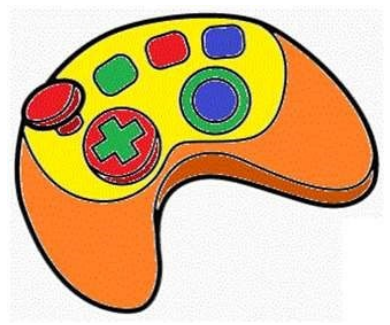

(a) Figura controle

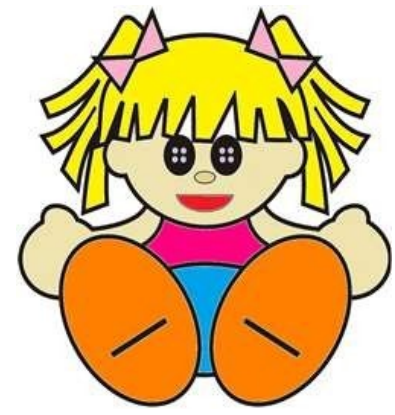

(b) Figura boneca
Figura 2: Exemplo de imagens que são coladas nos blocos lógicos

Para a interação com o jogo e o reconhecimento dos blocos lógicos, o desenvolvimento foi feito utilizando a Unity 3D. Seu uso se dá por meio de um dispositivo tátil com sistema operacional Android ou com um computador Windows com câmera. 


\subsection{Atividade com Blocos Lógicos}

As atividades com blocos lógicos foram projetadas para possibilitar a interação da criança com a interface gráfica por meio dos blocos lógicos. O jogo propõe atividades para o jogador e um recurso para que o usuário (professor ou o próprio aluno) crie suas próprias atividades.

Com vistas a ampliar a acessibilidade na perspectiva do design universal, incutiu-se no jogo retornos sonoros e o modo de jogo para deficientes visuais. $\mathrm{O}$ jogo apresenta retorno sonoro sempre que uma fase é iniciada, falando para o jogador qual o objetivo da fase. $\mathrm{O}$ jogo também apresenta um botão de fala o qual, ao ser selecionado, narra novamente o objetivo da fase. Essas funcionalidades auxiliam pessoas com deficiência cognitiva e visual. O modo de deficientes visuais altera o ambiente de jogo, proporcionando uma experiencia adequada para pessoas cegas ou com baixa visão.

5.2.1 Jogo padrão. O jogo apresenta dois módulos, sendo o primeiro o módulo de fases (ou atividades) criadas pelos desenvolvedores do jogo e disponíveis para jogar. O objetivo é dar subsidio para que o usuário possa jogar fases pré desenvolvidas e pensadas de forma que a dificuldade aumente gradativamente e que existam diversas variações de desafios.

Para o desenvolvimento desse modo foi utilizada uma base consolidada de atividades baseadas no livro "Blocos Lógicos: 150 Exercícios para Flexibilizar o Raciocínio"[8]. No livro, a autora desenvolve atividades especialmente para pais e educadores que buscam ampliar o raciocínio da criança e adolescente por meio de exercícios usando os blocos lógicos. Exemplos de atividades que foram implementadas no jogo são: agrupar blocos de mesma cor, agrupar blocos de características diferentes (exemplo, agrupar objetos de cores diferentes) e agrupar blocos que não apresentem uma determinada característica. Para cegos, um dos jogos que pode ser implementado é agrupar peças de mesmo formato, ou juntar peças de diferentes formatos e espessuras. Um ponto a ressaltar é que as fases para pessoas com deficiência visual aparecem para todos. Nestas, omitiram-se as atividades que envolvem cores.

Na Figura 3 é apresentada a tela do jogo. O objetivo é apresentado dentro do retângulo amarelo (colocar na tela um objeto grande), em baixo o botão de voz (representado pelo microfone), que ao apertalo, irá narrar o objetivo da fase e por último a seta de voltar que irá abrir o menu de opções. Mesmo apresentado um botão para narrar, sempre que a fase é iniciada, a narração do objetivo acontece.

$\mathrm{Na}$ Figura 4, é apresentado como funciona a interação entre o jogo e o usuário. O jogador deve colocar o objeto na frente da câmera e o bloco é identificado pelo programa e apresentado na tela. Se o jogador cumprir os objetivos da fase, ela é completa. A fase não é terminada em erro caso o jogar coloque a peça errada no ambiente.

5.2.2 Criação de fases. O segundo do módulo do jogo permite que pais ou professores, ou o próprio aluno, criem novas atividades no jogo. O foco do desenvolvimento do modo de Criação de fases está em permitir ao usuário utilizar de sua criatividade para conceber as fases que quiser, sem restrições de dificuldade ou crescimento linear de dificuldade.

\section{GRANDE}

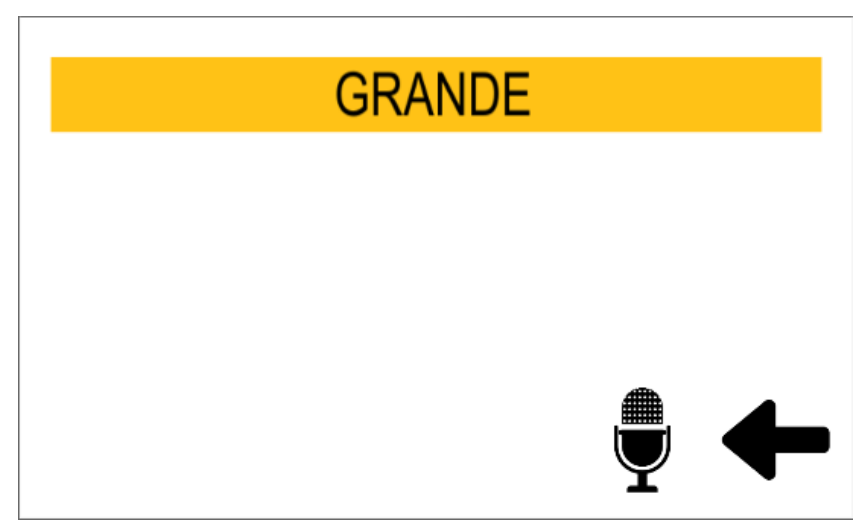

Figura 3: Modelo tela de jogo

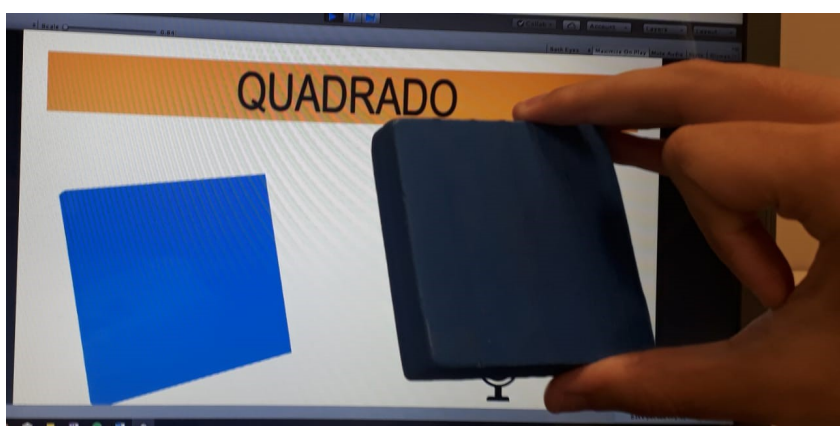

Figura 4: Interação jogador e jogo

Para esse modo existe a tela de criação de fases apresentada na Figura 5. O usuário pode nomear sua fase, definir quais as características do bloco que serão pedidas como objetivo e quantos desses blocos devem ser colocados em cena para que se complete a fase. Nessa tela são mostradas (em verde) todas as fases já criadas, permitindo que ela seja deletada.

O usuário não precisa selecionar todas as características de um bloco para criar a fase. Por exemplo, se o usuário desejar, pode criar uma fase que requeira três blocos vermelhos para completá-la, sem identificar outras características. Assim como, se ele quiser criar uma fase em que precise de um bloco vermelho, grande, grosso e quadrado ele também pode. As fases criadas podem ser selecionadas por um submenu na tela inicial, como observa-se na figura 5.

5.2.3 Deficientes visuais. O jogo permite o uso por deficientes visuais por meio de uma configuração, denominada modo cego. Nesse modo as atividade requerem do usuário somente o uso dos recursos sonoros e táteis para identificar as peças que respondem as questões. Como cada peça tem tamanhos e formas diferentes, o usuário pode se localizar por meio do seu tato.

A grande diferença desse modo para os outros modos de jogo é a remoção dos blocos de cor. Todas as outras características dos blocos (tamanho, espessura e forma) o usuário consegue identificar com o tato com exceção da cor. Todas as fases que apresentarem objetivos relacionados a cor dos blocos não serão apresentadas ao usuário. Essa opção funciona tanto para as fases do modo padrão quanto 


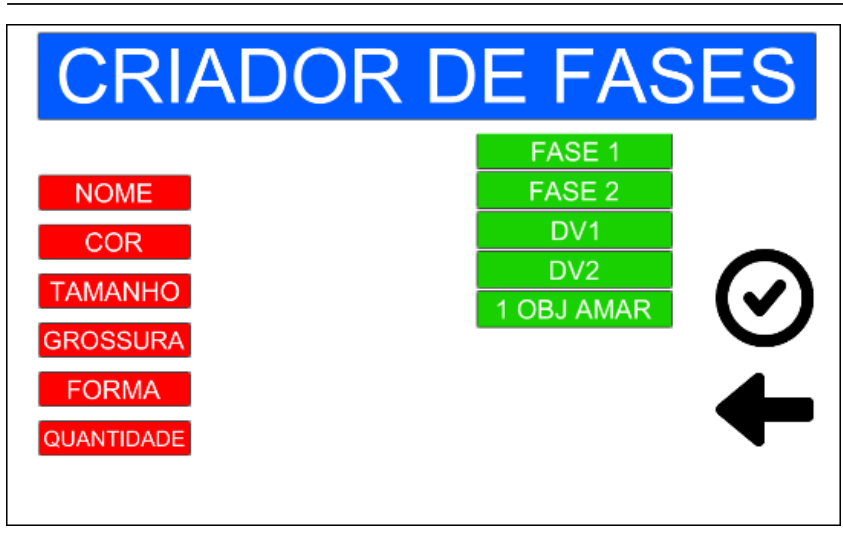

Figura 5: Tela de criação de fases

para as fases criadas pelos usuários. Como é possível observar pela Figura 6, a opção é ativada pelo menu iniciar.

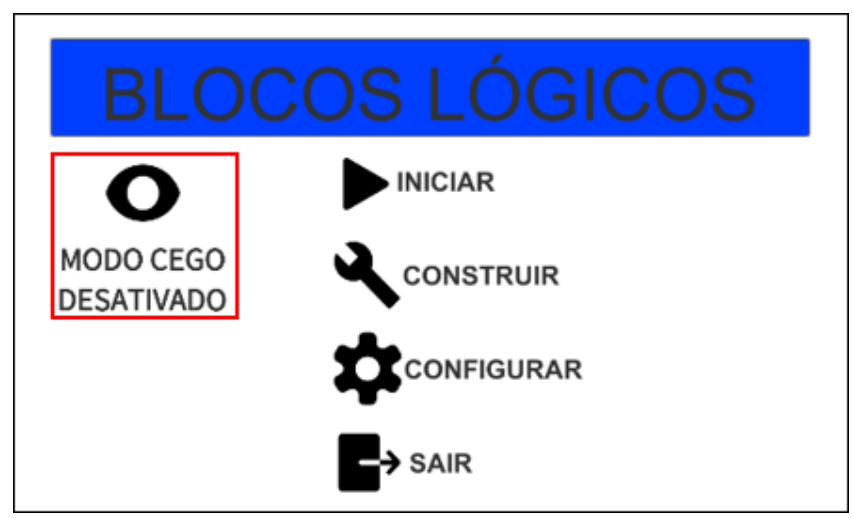

Figura 6: Modo de jogo para deficientes visuais

O maior problema é que, como o jogo não apresenta comandos de voz, uma pessoa completamente cega irá precisar de ajuda tanto para ativar o modo de jogo quanto para iniciar uma fase. Entretanto, as fases são passadas automaticamente, então, uma vez jogando, o usuário consegue terminar o jogo sem ajuda.

\section{CONSIDERAÇÕES FINAIS}

Discutiu-se nesse artigo o uso das interfaces tangíveis como instrumentos de acessibilidade em jogos digitais educacionais. $\mathrm{O}$ jogo desenvolvido sugere benefícios quando utilizado em sala de aula, pois com ele, a professora não irá precisar ficar corrigindo os exercícios passados para as crianças, podendo manter o foco nas crianças que estão precisando de sua ajuda. Além do mais, ele elabora atividades que muitas vezes a professora não iria pensar em criar. Ao invés de apenas deixar as crianças brincando sem propósito, as atividades didáticas irão contribuir para o desenvolvimento intelectual do aluno.

Espera-se que o uso dos blocos lógicos, como uma ferramenta de intermédio entre o usuário e um jogo digital seja uma maneira eficiente de utilizar materiais concretos para o auxílio do ensino da matemática, que usam, em sua grande maioria, de conceitos abstratos que são, geralmente, difíceis de serem entendidos pelas crianças.

Pretende-se realizar avaliação do jogo com estudantes e professoras, de forma a validar a proposta aqui desenvolvida. O jogo está funcional, porém, apresenta alguns pontos que podem ser aprimorados em trabalhos futuros:

- Identificação das peças: a identificação das peças é um dos principais problemas do jogo. Mesmo que a maneira escolhida pra identifica-las funcione, existe todo um preparo para que o jogo possa começar, como a impressão, recorte e colagem das figuras. O software apresenta um delay para identificar as peças, causando certa demora na operação. Para esse problema, seria necessário encontrar uma biblioteca específica para identificar formas ou desenvolver um código proprietário para a identificação dessas.

- Narração das fases: a narração das fases (o áudio referente a narração de cada uma das fases) é criada fora do jogo. Assim, as fases criadas pelos usuários ficam sem a narração. Quando se tenta abranger o maior número de usuários possíveis, narração é um ponto essencial para o entendimento e o pleno desenrolar da jogabilidade. Contornar esse problema necessitaria que o próprio jogo gerasse os áudios das fases. Para isso, é necessário de uma biblioteca que traduz o texto em fala. Dessa forma, todas as fases teriam sua narração (criadas in-game).

- Design: as fases do jogo são desenvolvidas pensadas no crescimento linear de dificuldade. De modo que as primeiras fases sejam mais fáceis, para explicar o jogo ao jogar, e as últimas necessitam que eles tenham que pensar mais. O problema nesse ponto é a interface gráfica. O jogo é simplório e não chama a atenção. Os menus são simples e não atiçam a curiosidade do usuário. Essa falta de gráficos chamativos pode afastar usuário e deixar pontos dos menus mais complicados de entender.

Seguindo como referencial os problemas elencados anteriormente, como trabalhos futuros, pode se citar: o re-design do projeto, fazendo com que ele apresente telas e menus chamativos e que a interface seja mais fácil de ser entendida; o desenvolvimento, ou estudo e implementação, de uma API (Interface de programação de aplicações) que transforme o texto da fase em áudio, para auxiliar o usuário com dificuldades mesmo mas fases criadas pelos usuários; e a implementação de um método mais eficiente de leitura dos blocos. O atual é funcional, mas apresenta várias falhas, como a dificuldade de identificar as peças menores e a necessidade de se imprimir e colar as imagens para se jogar. Se podem criar novos modelos de fases, para aumentar a variedade do jogo. Fases essas como formar objetos a partir do agrupamento de diferentes blocos; repetir uma sequência de objetos. Por exemplo, juntar dois círculos pequenos, um retângulo médio para formar um carrinho ou juntar um círculo pequeno e um retângulo médio para formar uma gangorra.

Acredita-se que esse software poderá ampliar a aprendizagem dos alunos, favorecendo a todos, independente de suas deficiências; auxiliando o professor, ou pais, na proposta de atividades lúdicas e pedagógicas. Este trabalho também contribui para as pesquisas 
em acessibilidade em jogos digitais, como a proposta de interfaces naturais para o usuário, ampliando seu acesso às tecnologias digitais.

\section{AGRADECIMENTOS}

Os autores agradecem ao Governo do Estado de Santa Catarina por ceder uma bolsa de pesquisa do artigo 170 da constituição do Estado.

\section{REFERÊNCIAS}

[1] K. Devlin. 2004. O Gene da Matemática: o Talento para Lidar com Números e a Evolução do Pensamento Matemático. Number 1. Record, Rio de Janeiro. 349 pages.

[2] Centre for Excellence in Universal Design. 2014. What is Universal Design http://universaldesign.ie/What-is-Universal-Design/

[3] Rabia Jafri, Asmaa Mohammed Aljuhani, and Syed Abid Ali. 2015. A tangible interface-based application for teaching tactual shape perception and spatial awareness sub-concepts to visually impaired children. Procedia Manufacturing 3 (2015), 5562-5569.

[4] Orazio Miglino, Andrea Di Ferdinando, Raffaele Di Fuccio, Angelo Rega, and Carlo Ricci. 2014. Bridging digital and physical educational games using RFID/NFC technologies. Fournal of e-Learning and Knowledge Society 10, 3 (2014).

[5] Augusto LP Nunes, Adriel O Radicchi, and Leonardo C Botega. 2011. Interfaces Tangíveis: Conceitos, Arquiteturas, Ferramentas e Aplicações. Realidade Virtual e Aumentada: aplicações e tendências (2011), 26-44.

[6] Bruna Carolina Rebello, Lucas Daniel Lira da Silva, and Adriana Gomes Alves. 2018. Desenvolvimento e análise de usabilidade de um jogo digital para o apoio ao processo de mediação cultural em museu: a caixa interativa de tartarugas marinhas. Anais do Computer on the Beach (2018), 402-411.

[7] A. Rubio, I.; Madariaga. 2012. Buenas prácticas de accesibilidad en videojuegos. Ministerio de Sanidad, Servicios Sociales e. Igualdad Secretaría de Estado de Servicios Sociales e Igualdad. Instituto de Mayores y Servicios Sociales (IMSERSO), Chapter 1.2.

[8] Simons M. S. 2011. Blocos lógicos: 150 exercícios para flexibilizar o raciocínio. Number 3. Editora Vozes, Rio de Janeiro. 216 pages.

[9] Cassiano Viana and André Raabe. 2018. Interface de programação tangível para produção de algoritmos sonoros. In Anais dos Workshops do Congresso Brasileiro de Informática na Educação, Vol. 7. 125.

[10] C. P. Viana and A. L. A. Raabe. 2019. Notação De Programação Tangível Para Produção De Algoritmos Sonoros. Biblioteca da UNIVAL (2019).

[11] Vuforia. 2017. Optimizing Targert Detection and Tracking Stability. https://library.vuforia.com/articles/Solution/Optimizing-Target-Detectionand-Tracking-Stability.html

[12] Oren Zuckerman, Saeed Arida, and Mitchel Resnick. 2005. Extending tangible interfaces for education: digital montessori-inspired manipulatives. In Proceedings of the SIGCHI conference on Human factors in computing systems. ACM, 859-868. 